\title{
Microstructure and Properties of Polyhydroxybutyrate-Chitosan-Nanohydroxyapatite Composite Scaffolds
}

\author{
L. Medvecky \\ Department of Electroceramics, Institute of Materials Research of SAS, Watsonova 47, 04001 Kosice, Slovakia \\ Correspondence should be addressed to L. Medvecky, lmedvecky@imr.saske.sk
}

Received 13 October 2011; Accepted 31 October 2011

Academic Editors: A. Bandyopadhyay and T. Ohura

Copyright (C) 2012 L. Medvecky. This is an open access article distributed under the Creative Commons Attribution License, which permits unrestricted use, distribution, and reproduction in any medium, provided the original work is properly cited.

\begin{abstract}
Polyhydroxybutyrate-chitosan-hydroxyapatite (PHB-CHT-HAP) composite scaffolds were prepared by the precipitation of biopolymer-nanohydroxyapatite suspensions and following lyophilisation. The propylene carbonate and acetic acid were used as the polyhydroxybutyrate and chitosan solvents, respectively. The high porous microstructure was observed in composites and the macroporosity of scaffolds (pore sizes up to $100 \mu \mathrm{m}$ ) rose with the chitosan content. It was found the reduction in both the PHB melting $\left(70^{\circ} \mathrm{C}\right)$ and thermal degradation temperatures of polyhydroxybutyrate and chitosan biopolymers in composites, which confirms the mutual ineraction between polymers and the decrease of PHB lamellar thickness. No preferential preconcentration of individual biopolymers was verified in composites, and the compressive strengths of macroporous PHB-CHT-HAP scaffolds were approximately 2.5 MPa. The high toxic fluorinated cosolvents were avoided from the preparation process.
\end{abstract}

\section{Introduction}

Composite biopolymer-calciumphosphate systems are very interesting from the point of view of the applications in reconstruction and regenerative medicine, maxillofacial surgery, and other medicine fields. The chitosan represents polysaccharides that have inductive and stimulation activity on connecticve tissue rebuilding [1]. Osteoblast-like cell growth in the calcium phosphate- $(10 \mathrm{wt} \%)$ reinforced chitosan scaffolds was studied by Y. Zhang and M. Zhang [2]. The nanohydroxyapatite addition to chitosan improved the bioactivity of composite scaffolds and affected on the apatite formation on them [3]. The bioresorption of nanohydroxyapatite was improved, and it was assumed that it was caused the lowered migration of nanoapatite particles into surrounding tissues by the addition of chitosan [4]. The poly(3hydroxybutyrate) (PHB) represents natural biodergadable and hydrophobic biopolymer. The porous hydroxyapatitepolyhydroxybutyrate-co-valerate scaffold ( $2 \mathrm{wt} \%$ hydroxyapatite) was prepared by the lyophilisation of suspension, and the results showed the rise in stiffness, strength, and improving in-vitro bioactivity of the scaffold [5]. The injection and compression moulding are the most utilized preparation method for the production of hydroxyapatitepolyhydroxybutyrate composites. The increase in interfacial shear strength and the enhanced endosteal bone growth were found in dry-blended and injection-moulded $30 \mathrm{wt} \%$ hydroxyapatite $-70 \mathrm{wt} \%$ polyhydroxybutyrate composite [6]. In polyhydroxybutyrate-chitosan blends prepared by mixing of the individual polymer solutions dissolved in fluorinated cosolvent, 1,1,1,3,3,3-hexafluoro-2-propanol, the decrease in polyhydroxybutyrate crystallinity with chitosan content was observed. After blends melting, the miscibility of polymers was verified with the strong intermolecular interaction between polyhydroxybutyrate and chitosan chains $[7,8]$.

In this paper, we studied the preparation, microstructure, and properties of the polyhydroxybutyrate-chitosanhydroxyapatite composite scaffolds using the polymer precipitation by mutual polymer solution mixing. This preparation process allows to prepare the above composite scaffolds without applying the toxic fluorinated cosolvent, whereas the propylenecarbonate and acetic acid were used as polyhydroxybutyrate (PHB) and chitosan (CHT) biopolymer solvents. 
Besides, our aim was to prepare relatively soft biocomposite material, which could be simply tamable to required shape.

\section{Materials and Methods}

2.1. Materials. Calcium-deficient nanohydroxyapatite (HAP) was synthesized by the coprecipitation of $\mathrm{Ca}\left(\mathrm{NO}_{3}\right)_{2} \cdot 4 \mathrm{H}_{2} \mathrm{O}$ (Sigma-Aldrich, analytical grade, concentration of 0.5 mol dm ${ }^{-3}$ ) and $\left(\mathrm{NH}_{4}\right)_{2} \mathrm{HPO}_{4}$ (Sigma-Aldrich, analytical grade, concentration of $0.5 \mathrm{~mol} \mathrm{dm}^{-3}$ ) solutions with a molar ratio of $\mathrm{Ca} / \mathrm{P}=1.66$. The aqueous solution of $\mathrm{Ca}^{2+}$ ions was slowly dropped to aqueous solution of phosphate ions during 1.5 hours. The $\mathrm{pH}$ was kept at 10.5 by adding of $\mathrm{NH}_{3}(\mathrm{aq})(1: 1)$. Ageing time was 72 hours. Precipitates were washed with distilled water and filtered over the membrane filter (Millipore, $0.2 \mu \mathrm{m}$ pore size). Nanohydroxyapatite (HAP) powders were dried at $110^{\circ} \mathrm{C}$ for 2 hours.

2.2. Composite Preparation. The composites with $80 \mathrm{wt} \%$ HAP content and various polyhydroxybutyrate (GoodFellow) to chitosan (SigmaAldrich, middle, $80 \%$ deacetylation degree) ratios $(3: 1,1: 1,1: 3)$ were prepared by the mutual mixing of HAP, PHB (propylenecarbonate was used as solvent), and chitosan solutions ( $1 \%$ acetic acid solution as solvent) in appropriate amounts. Note that the same solution volumes with different polymer concentrations were for the precipitation, and the pure PHB-HAP composite was precipitated after mixing of the suspension with acetic acid solution for satisfying similar preparation conditions. The mixing was done with a magnetic stirrer at $400 \mathrm{rpm}$. After 15 minutes, the acetone was slowly added to suspensions for the completely biopolymers precipitation. Final composites were filtered, washed with acetone, and dried at $50^{\circ} \mathrm{C}$ for 30 minutes, moulded to cylindrical form $(6 \mathrm{~mm} \mathrm{D} \times 12 \mathrm{~mm} \mathrm{H})$, freezed at $-20^{\circ} \mathrm{C}$, and lyophilised (Ilshin) for 6 hour.

\subsection{Methods}

2.3.1. Compressive Strength Measurements and In-Vitro Bioactivity Testing. The compressive strength of composites was measured on discs with dimensions of $6 \mathrm{~mm}$ in diameter and $12 \mathrm{~mm}$ in length. For each experimental group (5 samples), the compressive strengths were measured on a universal testing machine (LR5K Plus, Lloyd Instruments, Ltd.) at a crosshead speed of $0.5 \mathrm{~mm} / \mathrm{min}$. The in-vitro apatiteability forming of composites was analysed from the mass increments after soaking of samples in $100 \mathrm{~mL}$ of simulated body fluid [9] for 1 and 2 weeks at $37^{\circ} \mathrm{C}$. The SBF solutions during testing were exchanged after 3 days.

2.3.2. Characterization Methods. The thermal degradation and melting of composites were analysed by the differential scanning calorimetry (DSC) and thermogravimetry (TG) (Mettler, 2000C). The phase composition and crystallinity were studied by XRD diffraction analysis (Philips $\mathrm{X}^{\vee}$ Pert Pro) using $\mathrm{CuK} \alpha$ radiation and infrared spectroscopy (Specord M80). The microstructure of composite scaffolds was observed by a scanning electron microscopy (FE SEM
JEOL7000), and the HAP particle morphology was analysed using transmission electron microscopy (TEM, TESLA BS500). The optical fluorescence microscopy (inverted optical microscope Leica DM IL LED) with blue filter was used for verification of the distribution of individual biopolymers in composites whereas the $0.1 \%$ Nile red (acetone solution, prepared from the Nile blue A according to Greenspan et al. [10]) and $0.1 \%$ eosin Y (methanol solution) [11] were applied for the detection of $\mathrm{PHB}$ and chitosan, respectively. The HAP-specific surface was determined by the $\mathrm{N}_{2}$ adsorption method at $-196^{\circ} \mathrm{C}$ (GEMINI).

\section{Results and Discussion}

3.1. Microstructure Analysis of Composite Scaffolds. The HAP particles had spherical morphology with the average particle size around $50 \mathrm{~nm}$ (Figure 1(a)). The value of specific surface was $96 \mathrm{~m}^{2} / \mathrm{g}$, from which results the average particle size (for spherical particle shape approximation) equals $22 \mathrm{~nm}$. This value is comparable with one calculated from the XRD patterns. The SEM microstructures of composite scaffolds with various $\mathrm{PHB}$ : CHT ratios are shown in Figures 1(b), $1(\mathrm{c})$, and $1(\mathrm{~d})$. The composite with PHB:CHT $=3: 1$ (Figure 1(b)) had more compact microstructure, where a very small fraction of large $100 \mu \mathrm{m}$ pores and the high amount of irregular pores with dimension $<10 \mu \mathrm{m}$ can be observed. Despite increased amount of the large sphericalshaped pores with chitosan content in composites, the high amount of pores with average size of 10-20 $\mu \mathrm{m}$ was found in microstructures (Figures 1(c) and 1(d)). From the analysis of micrographs result that the microstructures of all samples are very porous and the micropores with dimensions less than $1 \mu \mathrm{m}$ are clearly visible too. Microstructure analysis verified that the main factor responsible for a large pores formation is the presence of sufficient fraction of the chitosan gel, in which is entrapped the high amount of water and this swelled gel has significantly enlarged volume than native chitosan powder. Besides, the chitosan supports the formation longer fibres or plates in composites and stabilizes walls of pores whereas they are not visible in composite with lower chitosan content. It can be observed in Figures $1(\mathrm{~b})-1(\mathrm{~d})$ that composite agglomerates are mutually interconnected via biopolymer fibres, which stabilizes the composite scaffold microstructure. Note that the measured composite scaffold densities were maximal at PHB : CHT = $1: 1\left(0.45 \mathrm{~g} / \mathrm{cm}^{-1}\right)$ and the porosities were about $80 \mathrm{vol} \%$. Thin $(<50 \mathrm{~nm})$ needle-like particles or dendrites were found in all microstructures whereas the highest width/length ratio was found in composite with $\mathrm{PHB}: \mathrm{CHT}=1: 1$. The distribution of individual biopolymers in composite with PHB:CHT = 1:1 was analysed by the fluorescence of biopolymers after interaction with the specific dye (Figure 2). The thin sample plates were cut from fractured surfaces of composite samples. From the comparison of fluorescence images results, both biopolymers are homogeneously distributed in composite microstructures without preferential preconcentration in any location. In these images is clearly visible more intensive fluorescence from chitosan (green 


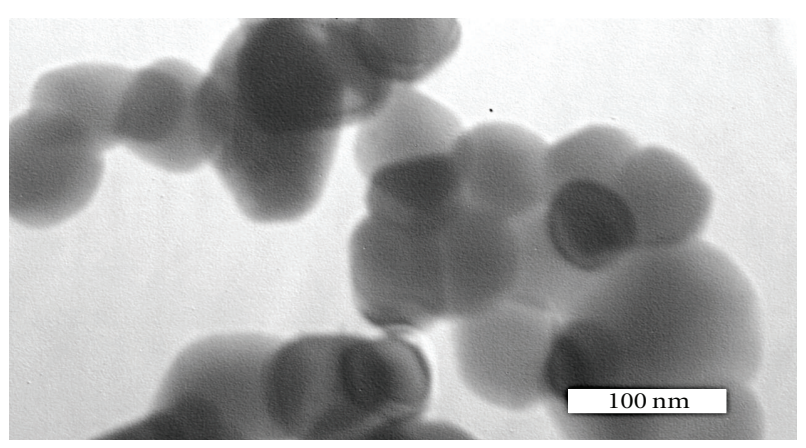

(a)

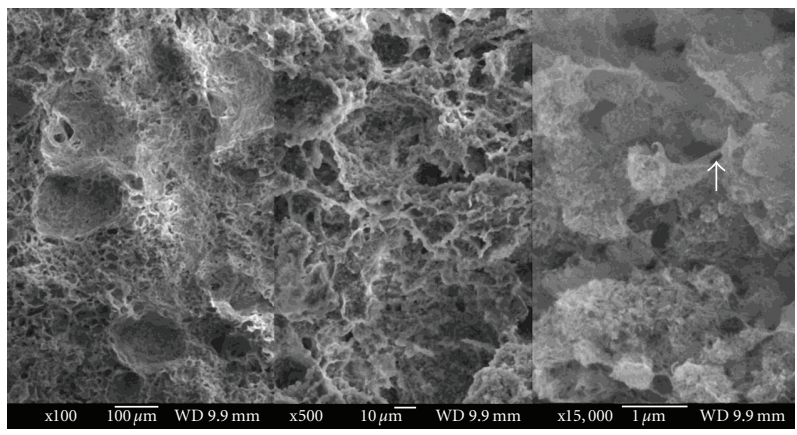

(c)

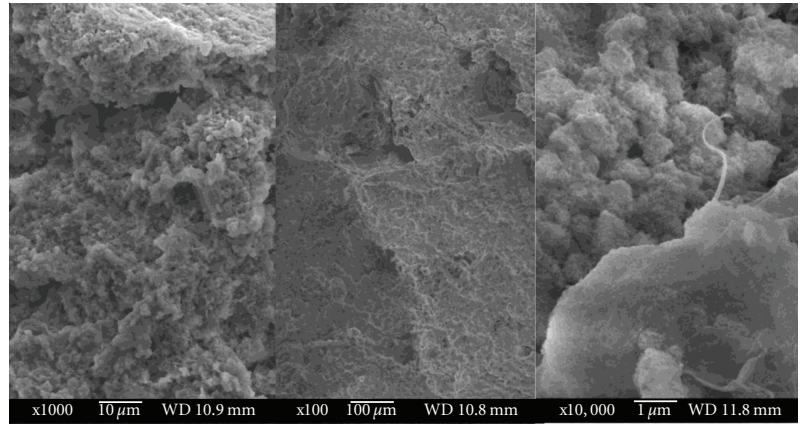

(b)

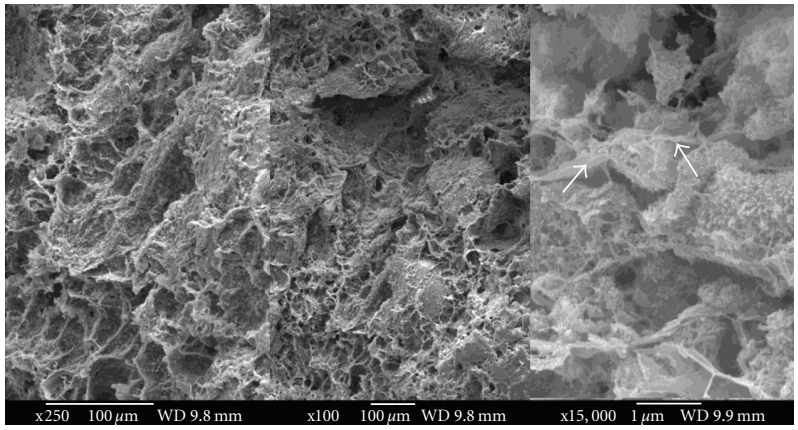

(d)

FIGURE 1: Morphology of HAP particles (a) and microstructure of composite scaffolds with different PHB : CHT ratio: (b) $3: 1$; (c) $1: 1$; (d) $1: 3$ (arrows show biopolymer fibre connections of agglomerates).

to brown colour in colour image) and PHB (orange-red colour in colour image) in pore walls, where is naturally the higher concentration of composite (and biopolymers). Thus, composite fibres or plates, which form the pore walls, contain both biopolymers.

3.2. XRD and IR Analysis of Composites. The XRD pattern of HAP verifies the presence of nanoapatite-like phase (JCPDS 24-0033), and the crystallinity size calculated from the reflections of (002) hydroxyapatite plane using the Scherrer equation was about $30 \mathrm{~nm}$. No significant changes were observed in the XRD composite patterns (Figure 3) at different PHB: CHT ratios. Besides, reflections from HAP planes and reflections from (020) and (110) PHB planes were clearly visible in the XRD patterns, which confirms the presence of significant PHB fraction in crystalline state. The CHT precipitated mainly in amorphous state. Very small increase of the HAP peak widths in composites was found only that corresponds with partially HAP particle dissolution in weak acid suspensions.

The IR spectra of composites are compared in Figure 4. The characteristic vibration of $\mathrm{PO}_{4}{ }^{3-}$ group located at 1050, 1100 , and $962 \mathrm{~cm}^{-1}$ (antisymmetric $\left(\nu_{3}\right)$ and symmetric $\left(\nu_{1}\right)$ P-O stretching vibrations) and $\mathrm{O}-\mathrm{P}-\mathrm{O}$ bending $\left(\nu_{4}\right)$ vibrations at 565 and $603 \mathrm{~cm}^{-1}$ can be found in HAP (Figure 3, curve (a)) [12]. Also, $v_{2}$ and $\nu_{3}$ modes of $\mathrm{CO}_{3}{ }^{2-}$ are located at wave numbers of 870 and $1400-1550 \mathrm{~cm}^{-1}$, the librational mode of $\mathrm{OH}$ hydroxyapatite group at $630 \mathrm{~cm}^{-1}$ [13], the broad band around $1650 \mathrm{~cm}^{-1}$ indicate adsorbed $\mathrm{H}_{2} \mathrm{O}$ (Figures 4(a), curve (b) and 4(b), curve (c)). From the detailed analysis of carbonate bands, it results that the $\mathrm{AB}$ type of carbonated HAP is formed by the $\mathrm{CO}_{2}$ adsorption from air because peaks $1450 \mathrm{~cm}^{-1}, 1420 \mathrm{~cm}^{-1}$, and $1550 \mathrm{~cm}^{-1}$ were found in spectrum. In the spectra of PHBHAP composite (Figures 4(a) curve (c) and 4(b) curve (e)), besides HAP bands, the band from $\mathrm{C}=\mathrm{O}$ stretching vibration (from PHB) at 1725 with shoulder at $1750 \mathrm{~cm}^{-1}$, bands at 1280,1230 , and $1180 \mathrm{~cm}^{-1}$, ascribed to the stretching vibrations of the $\mathrm{C}-\mathrm{O}-\mathrm{C}$ ester groups and bending $\mathrm{CH}_{2}$ , $\mathrm{CH}_{3}$-group vibrations under $1000 \mathrm{~cm}^{-1}$ were observable [14]. No shifts in the peak locations of carbonyl and ester bonds vibrations were found but the peak at $870 \mathrm{~cm}^{-1}$ from $\mathrm{CO}_{3}{ }^{2-}$ vibration in HAP vanished (bands at $1400-1550 \mathrm{~cm}^{-1}$ are overlapped with PHB vibration peaks) from spectra. In the case of three component systems (Figure 4(a) curve (d) and 4(b), curve (d)), the chitosan (Figures 4(a) curve (a), and 4(b) curve (a)) amide I $\mathrm{C}=\mathrm{O}$ vibration band at $1650 \mathrm{~cm}^{-1}$ cannot be clearly resolved in spectrum because of its overlapping with the band of physisorbed $\mathrm{H}_{2} \mathrm{O}$, the amide II N-H deformation vibration bands at $1550 \mathrm{~cm}^{-1}$, and band around $1050 \mathrm{~cm}^{-1}$ corresponding to stretching $\mathrm{C}-$ $\mathrm{O}$ vibrations which are visible in spectrum $[15,16]$. No shift was observed in stretching vibrations of the PHB carbonyl or $\mathrm{C}-\mathrm{O}$ ester group after chitosan mixing. The intensity of $\mathrm{PHB}$ carbonyl vibration in composites at $1750 \mathrm{~cm}^{-1}$ significantly increased in comparison with the peak at $1725 \mathrm{~cm}^{-1}$.

3.3. TG and DSC Measurements, Mechanical Properties and In-Vitro Bioactivity of Composites. Results of TG and DSC 


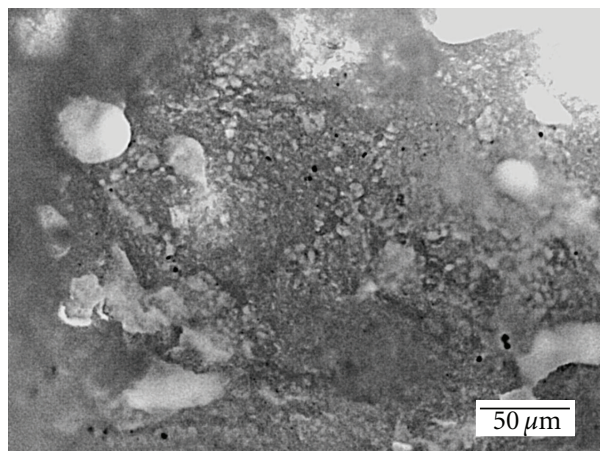

(a)

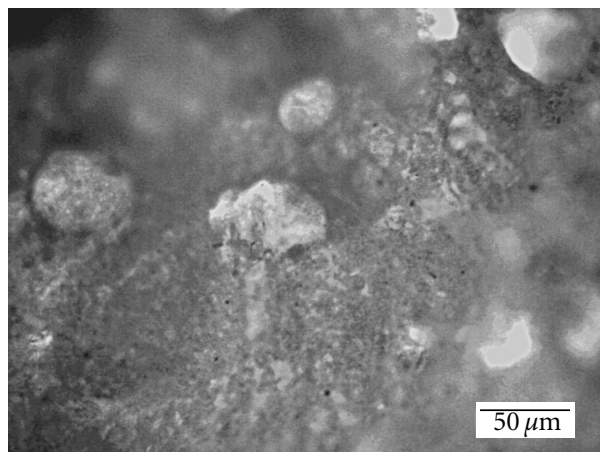

(c)

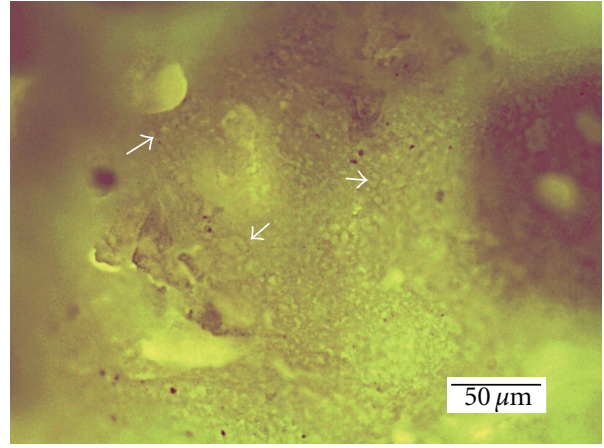

(b)

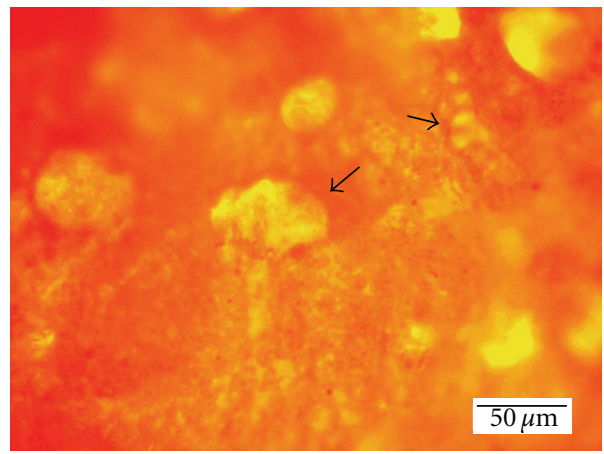

(d)

FIgURE 2: Optical micrographs of composite scaffolds with PHB:CHT $=1: 1$ in transmitted (a, c) and fluorescence mode (b) eosin Y (chitosan marker), (d) Nile red (PHB marker) (arrows show pore walls).

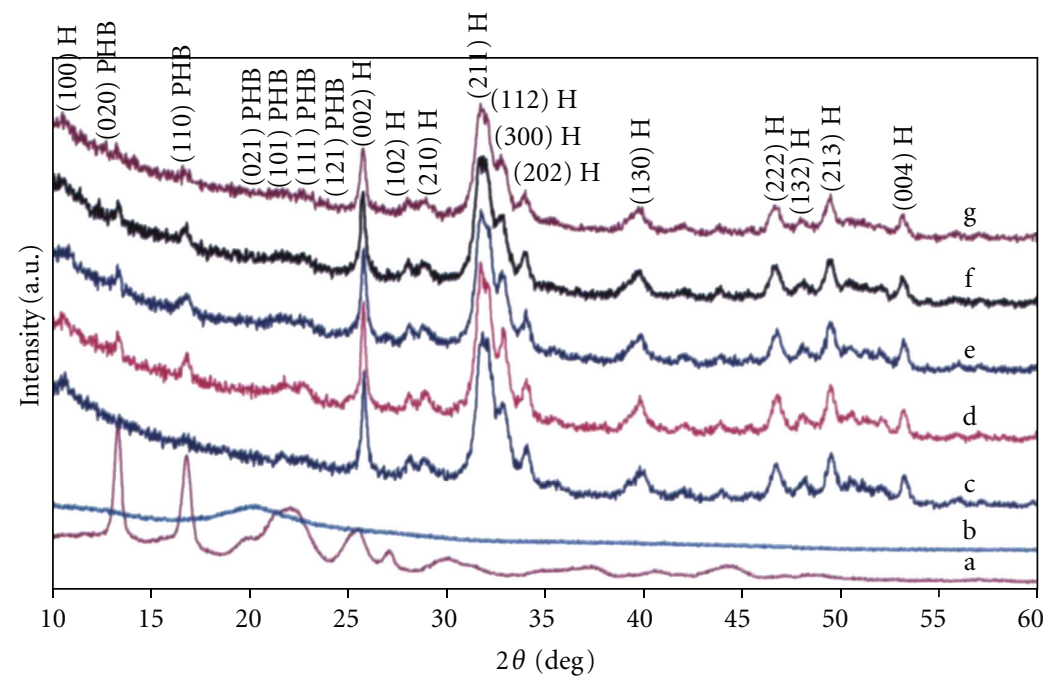

Figure 3: XRD patterns of composites with different PHB: CHT ratio. ((a) pure PHB; (b) pure chitosan; (c) pure HAP; (d) PHB: CHT = $3: 1$; (e) $1: 1$; (f) $1: 3$; (g) $0: 1$ ). (H: hydroxyapatite lines).

measurements of samples are shown in Figure 5. Two characteristic endoeffects with maxima at 182 and $292^{\circ} \mathrm{C}$ were found on the DSC curve of PHB (Figure 5(a), curve a), which corresponds to melting temperature and the PHB decomposition with rapid mass losses on TG curve (Figure 5(b), curve 1). Three endoeffects at 181, 230, and $290^{\circ} \mathrm{C}$ are visible on PHB-HAP composite DSC curve whereas approximately $90 \%$ of $\mathrm{PHB}$ amount decomposed at $230^{\circ} \mathrm{C}$ and $10 \%$ in the second stage of decomposition at $290^{\circ} \mathrm{C}$ (Figures 5(a), curve b, and 5(b) curve 2). After addition of third component (chitosan) to composite, three endoeffects at 163,181 (PHB melting), and $238^{\circ} \mathrm{C}$ from 


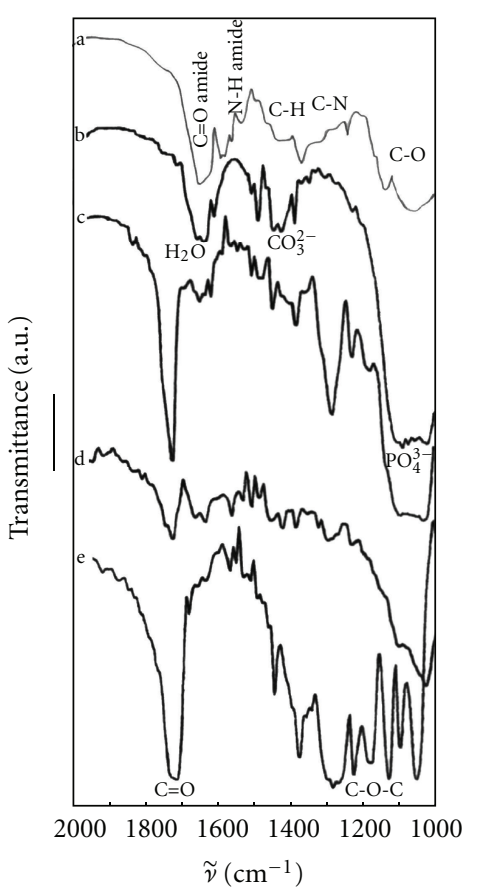

(a)

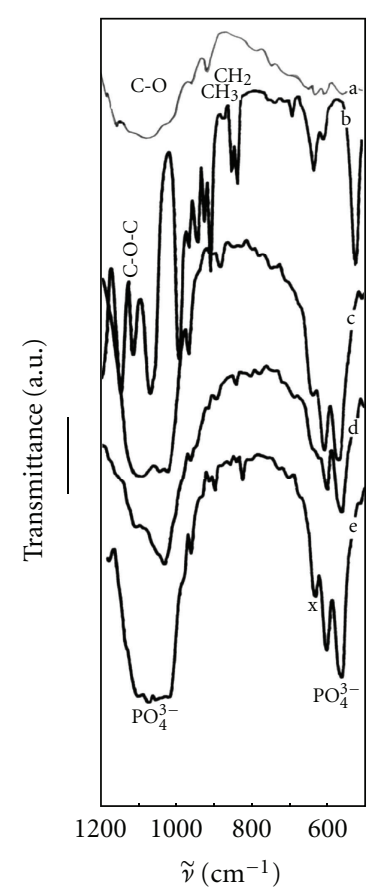

(b)

FIGURE 4: IR spectra of composites and pure components. (a), curve a and (b) curve a: pure chitosan; (a) curve b and (b) curve c: pure HAP; (a) curve c and (b) curve e: PHB-HAP composite; (a) curve d and (b) curve d: composite with PHB: CHT = 1:3; (a) curve e and (b) curve b: pure $\mathrm{PHB}$ ) (x-bending $\mathrm{P}-\mathrm{OH}$ in hydroxyapatite).

the PHB decomposition and single wide exoeffect at $290^{\circ} \mathrm{C}$ were observed (Figures 5(a) curve c, and 5(b) curve 3 ). The exoeffect represents the chitosan thermal decomposition, where the peak integral intensity rose with the chitosan content in composites. Besides, it can be observable the small temperature shift to lower temperature or the presence of shoulder on low temperature peak side as the consequence of the addition of both the chitosan exo- and PHB endoeffects (at $230^{\circ} \mathrm{C}$ ). The pure chitosan (Figures $5(\mathrm{a})$, curve $\mathrm{f}$, and 5(b) curve 6) decomposes in three steps as it can be visible from TG curve-water release up to $150^{\circ} \mathrm{C}$, the weight loss between 200 and $300^{\circ} \mathrm{C}$ may be related to the amine units decomposition, saccharide units are degraded above $300^{\circ} \mathrm{C}$ and decomposition finished around $600^{\circ} \mathrm{C}$ [17]. On the chitosan DSC curve, two large exoeffects are observableat 310 and $550^{\circ} \mathrm{C}$ with "exoplateau" among peaks. From the comparison of TG curves of composites, it results that they shift slowly to higher temperatures with the chitosan content but curves are smooth and the single inflex point was found after their numerical differentiation only.

The IR spectroscopy verified changes in crystallinity of PHB, where the increase in intensity of peak at $1750 \mathrm{~cm}^{-1}$ was observed after the chitosan addition, and the intermolecular bonding between biopolymers was not confirmed. This peak was also present in the carbonyl vibration band of PHBHAP composite but with lower intensity and it corresponds to rise of the amorphous fraction in PHB [14]. Ikejima et al. [15] confirmed by ${ }^{13} \mathrm{C}$ NMR spectroscopy the intermolecular bonding between the PHB carbonyl and chitosan amide groups and showed the increase of amorphous PHB phase component with chitosan content in the PHB-chitosan composites. Besides, on the DSC curves of these composites, the low temperature $\mathrm{PHB}$ melting point at $160^{\circ} \mathrm{C}$ and the increase of endoeffect intensity at this temperature with chitosan content were found, which was caused by the miscibility of amorphous PHB phase and chitosan. Similar dependence of the PHB melting point depression was found by Cheung et al. [7] and the intermolecular interaction between biopolymers was verified using ${ }^{1} \mathrm{H}$ NMR spectroscopy. Ikejima and Inoue [8] showed that the suppress of the PHB melting point in the blends is caused by the decrease in lamellar thickness of the PHB crystallites, and the rigid chitosan molecules make PHB molecules in the blends inflexible and suppress the crystallization of PHB. Sudesh et al. [18] found variation in melting temperature as a function of the inverse lamellar thickness for meltcrystallized PHB and melting point reduction from 180 to $160^{\circ} \mathrm{C}$ correspond with the decrease in lamellar thickness from $10 \mathrm{~nm}$ to $5 \mathrm{~nm}$. These facts clearly showed that the endoeffect at $163^{\circ} \mathrm{C}$ represents melting of the amorphous PHB formed after chitosan addition to the PHB-CHT-HAP composites. The amorphous PHB in composites creates, as a result of miscibility, mutual interaction between biopolymers and PHB lamellar thickness decrease despite the different preparation procedure and miscellanous solvents used for biopolymer dissolution. 


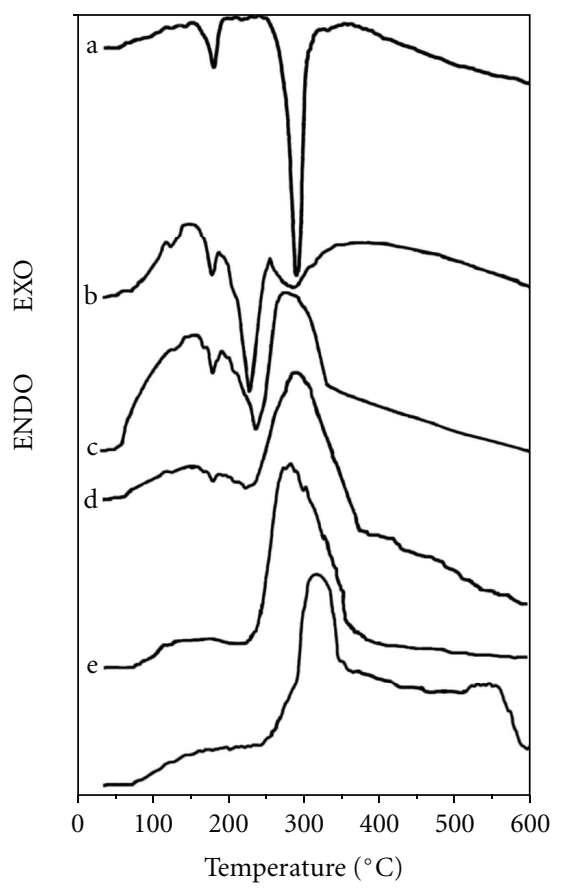

(a)

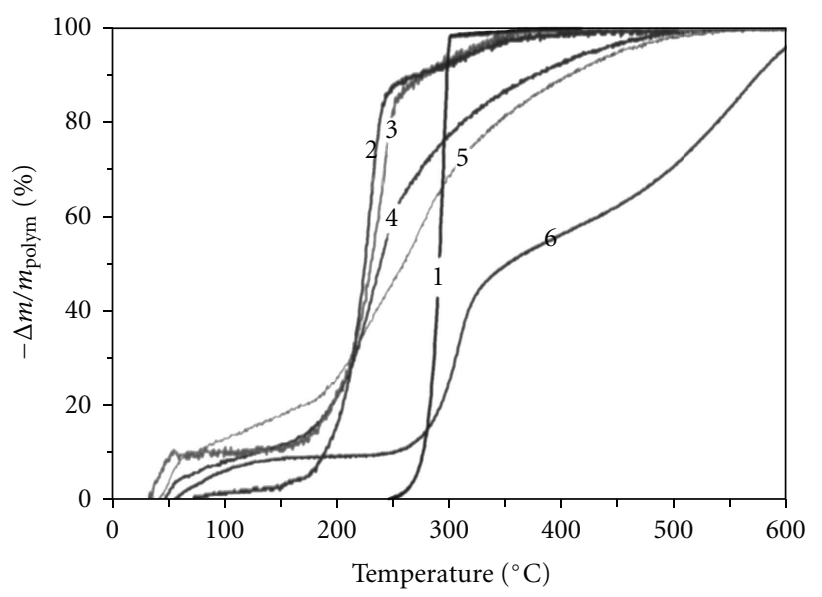

(b)

FIgUre 5: DSC (a) (a: pure PHB; b: PHB-HAP composite; c: composite with $\mathrm{PHB}: \mathrm{CHT}=3: 1$; d: composite with PHB: CHT $=1: 1$; e: composite with $\mathrm{PHB}: \mathrm{CHT}=1: 3$; f: pure chitosan) and TG ((b) $y$-axis represents the ratio of mass losse to total biopolymer content in composite) (curve 1: pure PHB; curve 2: PHB-HAP composite; curve 3: composite with PHB: $\mathrm{CHT}=3: 1$; curve 4: composite with $\mathrm{PHB}: \mathrm{CHT}=1: 1$; curve 5: composite with $\mathrm{PHB}: \mathrm{CHT}=1: 3$; curve 6: pure chitosan) analysis of composites.

The thermal decomposition of both biopolymers in composites was strongly affected by the addition of nanohydroxyapatite. The PHB thermal decomposition in PHB-HAP composite was shifted about $70^{\circ} \mathrm{C}$ to lower temperature in comparison with pure PHB. Chen and Wang [19] showed approximately $20^{\circ} \mathrm{C}$ depress in the degradation temperature after $30 \mathrm{wt} \%$ addition of HAP to polyhydroxybutyrate-co-valerate biopolymer (composite

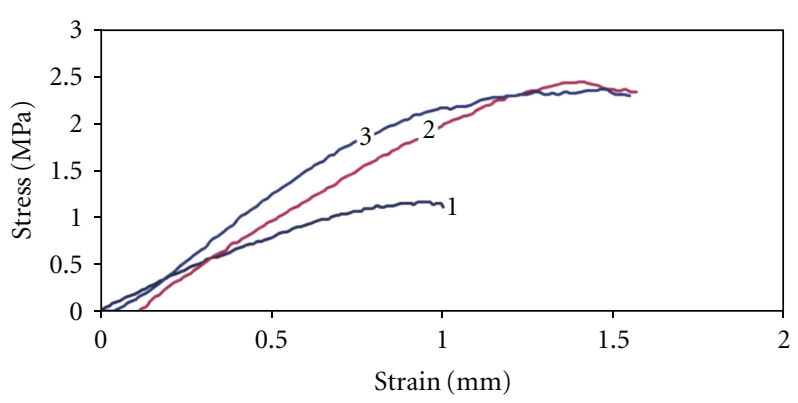

FIGURE 6: Stress-strain curves of composite scaffolds with different PHB : CHT ratio. (curve (1) 3:1; curve (2) 1:1; curve (3) $1: 3$ ).

was prepared by compression moulding). Misra et al. [20] found similar shift in the PHB decomposition temperature (from 290 to $230^{\circ} \mathrm{C}$ ) in PHB-bioglass composite foams. Kim et al. [21] verify that $\mathrm{Ca}^{2+}$ ions enhance and catalyse the depolymerisation of $\mathrm{PHB}$ molecules in very low concentration and reduce thermal decomposition temperature. The calcium ions act as Lewis acid that interacts with carboxyl group facilitating the formation of the double bond in crotonyl unit. Csomorová et al. [22] showed that the degradation temperature was influenced even in powder $\mathrm{PHB}-\mathrm{CaO}$ mixtures. We believe that in the case of composites with HAP addition, the same effect of calcium ions was manifested because HAP has a positively surface zeta potential in acid and weak alkaline solutions [23]. From the TG and DSC analysis, it clearly results that the mechanism of chitosan thermal degradation was significantly changed in composite systems, where the multistage degradation mechanism with distinct thermal steps was changed to almost single stage one. The degradation was finished at about $200^{\circ} \mathrm{C}$ lower temperature than in the pure chitosan. This facts could be the result of biopolymer interaction of the surrounding hydrophilic chitosan chains with hydrophobic PHB macromolecules [8], which make impossible to connect chitosan chains into larger structures and weaken intermolecular interactions. In the microstructures, were found the fine crystallities or dendrities formed during the crystallization of PHB polymer, which contains nanohydroxyapatite. The formation of needle-like $\mathrm{PHB}$ crystallites from propylene carbonate, observed by Organ et al. [24] and Iwata et al. [25] during the precipitation of PHB, covalerates copolymer from chloroform-ethanol solutions.

The compressive strength (CSs) of composite scaffolds rose with the chitosan content, and they equal to $1.1 \pm$ $0.2,2.3 \pm 0.2$, and $2.5 \pm 0.3 \mathrm{MPa}$ for composites with PHB : CHT $=3: 1,1: 1,1: 3$. The PHB-HAP composite disintegrated under weak loading. From the comparison of typical composite scaffold stress-strain curves (Figure 6), results rise in the plasticity of composites with the chitosan content because of the higher fraction of larger pores in microstructure. The gradual reduction of the composite scaffold CSs (no significant differences between composites with $\mathrm{PHB}: \mathrm{CHT}=1: 1,1: 3)$ to $1.8 \pm 0.2$ 
TABLE 1: The changes in masses of composites after soaking in SBF for 1 and 2 weeks.

\begin{tabular}{|c|c|c|c|}
\hline \multirow{2}{*}{$\begin{array}{l}\text { Soaking } \\
\text { Time/week }\end{array}$} & \multicolumn{3}{|c|}{ Mass increments/mass \% } \\
\hline & $80 \%$ HAP-20\% (25\%CHT + 75\% & $80 \% \mathrm{HAP}-20 \%(50 \% \mathrm{CHT}+50 \% \mathrm{PHB})$ & $80 \% \mathrm{HAP}-20 \%(75 \% \mathrm{CHT}+25 \% \mathrm{PHB})$ \\
\hline 1 & $13.2 \pm 0.8$ & $14.1 \pm 0.9$ & $12.3 \pm 1.1$ \\
\hline 2 & $17.8 \pm 1$ & $16.7 \pm 0.8$ & $20 \pm 1.5$ \\
\hline
\end{tabular}

and $1.6 \pm 0.3 \mathrm{MPa}$ after SBF soaking for 1 and 2 weeks, respectively, was found, which confirms slow degradation of the biopolymer matrix in SBF. Li et al. [26] synthesized nanohydroxyapatite-chitosan composite by the coprecipitation method, moulded in clava for obtaining dense microstructure, and CSs were around $100 \mathrm{MPa}$. Y. Zhang and M. Zhang [27] prepared the CHT- $\beta$ tricalcium phosphate composites with $80 \mathrm{vol} \%$ porosities by the lyophilisation of suspension and they had very low CS (around 0.3 MPa). The CSs of porous hydroxyapatite or calcium phosphate ceramics ( $80 \%$ porosity) were low and they do not exceed $0.4 \mathrm{MPa}$ [28]. In the wollastonite-polyhydroxybutyrate-covalerate composite with $60 \mathrm{wt} \%$ of wollastonite and high porous microstructure, CS equals 0.28 MPa [19]. Prepared biocomposites are soft and the mutual interconnections of individual composite components are sufficient for manipulation and mechanical treatment like cutting with scalpel.

Results of the in-vitro apatite-ability forming of composites (Table 1) showed that the mass increments in composites were independent on biopolymer ratio, where 17-20 mass \% increments were observed after 2 weeks soaking in SBF. This fact is understandable because the contents of hydroxyapatite bioactive component in composites were the same. Note that none mass losses verified the slow degradation of biopolymers during soaking only.

\section{Conclusion}

The results of experimental work can be summarized in the following points.

(1) High porous microstructure was observed in composite scaffolds and the macroporosity of scaffolds rose with the chitosan content in composites.

(2) Rise in amount of the amorphous PHB component was found after chitosan addition to the PHB-HAP mixture.

(3) Reductions in both the PHB melting and thermal degradation temperatures of $\mathrm{PHB}$ and chitosan biopolymers in composites were noted, which confirms mutual ineraction between polymers and the decrease of PHB lamellar thickness.

(4) Biopolymers were homogeneously distributed in composite scaffold microstructures.

(5) Compressive strengths of macroporous PHB-CHTHAP scaffolds were approximately $2.5 \mathrm{MPa}$.
(6) High nanohydroxyapatite loading of biopolymer matrix was achieved, wich preserves the appropriate in-vitro apatite-ability forming of composites.

(7) Composite scaffolds were prepared without applying of the high toxic fluorinated co-solvents.

\section{Acknowledgments}

This work was supported by the Slovak Grant Agency of the Ministry of Education of the Slovak Republic and the Slovak Academy of Sciences, Project. no. 2/0026/11 and the project "Advanced implants seeded with stem cells for hard tissues regeneration and reconstruction," which is supported by the Operational Program "Research and Development" financed through European Regional Development Fund.

\section{References}

[1] R. Muzzarelli, V. Baldassarre, F. Conti et al., "Biological activity of chitosan. Ultrastructural study," Biomaterials, vol. 9, no. 3, pp. 247-252, 1988.

[2] Y. Zhang and M. Zhang, "Cell growth and function on calcium phosphate reinforced chitosan scaffolds," Journal of Materials Science: Materials in Medicine, vol. 15, no. 3, pp. 255-260, 2004.

[3] L. Kong, Y. Gao, G. Lu, Y. Gong, N. Zhao, and X. Zhang, "A study on the bioactivity of chitosan/nano-hydroxyapatite composite scaffolds for bone tissue engineering," European Polymer Journal, vol. 42, no. 12, pp. 3171-3179, 2006.

[4] R. Murugan and S. Ramakrishna, "Bioresorbable composite bone paste using polysaccharide based nano hydroxyapatite," Biomaterials, vol. 25, no. 17, pp. 3829-3835, 2004.

[5] K. S. Jack, S. Velayudhan, P. Luckman, M. Trau, L. Grøndahl, and J. Cooper-White, "The fabrication and characterization of biodegradable HA/PHBV nanoparticle-polymer composite scaffolds," Acta Biomaterialia, vol. 5, no. 7, pp. 2657-2667, 2009.

[6] J. C. Knowles, G. W. Hastings, H. Ohta, S. Niwa, and N. Boeree, "Development of a degradable composite for orthopaedic use: in vivo biomechanical and histological evaluation of two bioactive degradable composites based on the polyhydroxybutyrate polymer," Biomaterials, vol. 13, no. 8, pp. 491-496, 1992.

[7] M. K. Cheung, K. P. Y. Wan, and P. H. Yu, "Miscibility and morphology of chiral semicrystalline poly-(R)-(3hydroxybutyrate)/chitosan and poly-(R)-(3-hydroxybutyrateco-3-hydroxyvalerate)/chitosan blends studied with DSC, $1 \mathrm{H}$ T1 and T1 $\rho$ CRAMPS," Journal of Applied Polymer Science, vol. 86, no. 5, pp. 1253-1258, 2002. 
[8] T. Ikejima and Y. Inoue, "Crystallization behavior and environmental biodegradability of the blend films of poly(3hydroxybutyric acid) with chitin and chitosan," Carbohydrate Polymers, vol. 41, no. 4, pp. 351-356, 2000.

[9] A. C. Tas, "Synthesis of biomimetic Ca-hydroxyapatite powders at $37^{\circ} \mathrm{C}$ in synthetic body fluids," Biomaterials, vol. 21, no. 14, pp. 1429-1438, 2000.

[10] P. Greenspan, E. P. Mayer, and S. D. Fowler, "Nile red: a selective fluorescent stain for intracellular lipid droplets," Journal of Cell Biology, vol. 100, no. 3, pp. 965-973, 1985.

[11] E. Slyusareva, A. Sizykh, A. Tyagi, and A. Penzkofer, "Spectral and photophysical properties of fluorone dyes in bio-related films and methanol," Journal of Photochemistry and Photobiology A, vol. 208, no. 2-3, pp. 131-140, 2009.

[12] R. N. Panda, M. F. Hsieh, R. J. Chung, and T. S. Chin, "FTIR, XRD, SEM and solid state NMR investigations of carbonate-containing hydroxyapatite nano-particles synthesized by hydroxide-gel technique," Journal of Physics and Chemistry of Solids, vol. 64, no. 2, pp. 193-199, 2003.

[13] A. Slosarczyk, Z. Paszkiewicz, and C. Paluszkiewicz, "FTIR and XRD evaluation of carbonated hydroxyapatite powders synthesized by wet methods," Journal of Molecular Structure, vol. 744-747, pp. 657-661, 2005.

[14] A. Padermshoke, Y. Katsumoto, H. Sato, S. Ekgasit, I. Noda, and Y. Ozaki, "Melting behavior of poly(3-hydroxybutyrate) investigated by two-dimensional infrared correlation spectroscopy," Spectrochimica Acta Part A, vol. 61, no. 4, pp. 541550, 2005.

[15] T. Ikejima, K. Yagi, and Y. Inoue, "Thermal properties and crystallization behavior of poly(3-hydroxybutyric acid) in blends with chitin and chitosan," Macromolecular Chemistry and Physics, vol. 200, no. 2, pp. 413-421, 1999.

[16] F. Chen, Z. C. Wang, and C. J. Lin, "Preparation and characterization of nano-sized hydroxyapatite particles and hydroxyapatite/chitosan nano-composite for use in biomedical materials," Materials Letters, vol. 57, no. 4, pp. 858-861, 2002.

[17] S. Choe, Y. J. Cha, H. S. Lee, J. S. Yoon, and H. J. Choi, "Miscibility of poly(3-hydroxybutyrate-co-3-hydroxyvalerate) and poly(vinyl chloride) blends," Polymer, vol. 36, no. 26, pp. 4977-4982, 1995.

[18] K. Sudesh, H. Abe, and Y. Doi, "Synthesis, structure and properties of polyhydroxyalkanoates: biological polyesters," Progress in Polymer Science, vol. 25, no. 10, pp. 1503-1555, 2000.

[19] L. J. Chen and M. Wang, "Production and evaluation of biodegradable composites based on PHB-PHV copolymer," Biomaterials, vol. 23, no. 13, pp. 2631-2639, 2002.

[20] S. K. Misra, T. I. Ansari, S. P. Valappil et al., "Poly(3hydroxybutyrate) multifunctional composite scaffolds for tissue engineering applications," Biomaterials, vol. 31, no. 10, pp. 2806-2815, 2010.

[21] K. J. Kim, Y. Doi, and H. Abe, "Effects of residual metal compounds and chain-end structure on thermal degradation of poly(3-hydroxybutyric acid)," Polymer Degradation and Stability, vol. 91, no. 4, pp. 769-777, 2006.

[22] K. Csomorová, J. Rychlý, D. Bakoš, and I. Janigová, “The effect of inorganic additives on the decomposition of poly (betahydroxybutyrate) into volatile products," Polymer Degradation and Stability, vol. 43, no. 3, pp. 441-446, 1994.

[23] C. Wang, J. Ma, W. Cheng, and R. Zhang, "Thick hydroxyapatite coatings by electrophoretic deposition," Materials Letters, vol. 57, no. 1, pp. 99-105, 2002.
[24] S. J. Organ, J. Li, A. E. Terry, J. K. Hobbs, and P. J. Barham, "Crystallization of hydroxybutyrate oligomers. Part 2. Growth and thickening of solution grown crystals observed in situ using synchrotron radiation," Polymer, vol. 45, no. 26, pp. 8925-8936, 2004.

[25] T. Iwata, Y. Doi, S. I. Nakayama, H. Sasatsuki, and S. Teramachi, "Structure and enzymatic degradation of poly(3hydroxybutyrate) copolymer single crystals with an extracellular PHB depolymerase from Alcaligenes faecalis T1," International Journal of Biological Macromolecules, vol. 25, no. 1-3, pp. 169-176, 1999.

[26] Z. Li, L. Yubao, Y. Aiping, P. Xuelin, W. Xuejiang, and Z. Xiang, "Preparation and in vitro investigation of chitosan/nanohydroxyapatite composite used as bone substitute materials," Journal of Materials Science: Materials in Medicine, vol. 16, no. 3, pp. 213-219, 2005.

[27] Y. Zhang and M. Zhang, "Synthesis and characterization of macroporous chitosan/calcium phosphate composite scaffolds for tissue engineering," Journal of Biomedical Materials Research, vol. 55, no. 3, pp. 304-312, 2001.

[28] K. Rezwan, Q. Z. Chen, J. J. Blaker, and A. R. Boccaccini, "Biodegradable and bioactive porous polymer/inorganic composite scaffolds for bone tissue engineering," Biomaterials, vol. 27, no. 18, pp. 3413-3431, 2006. 

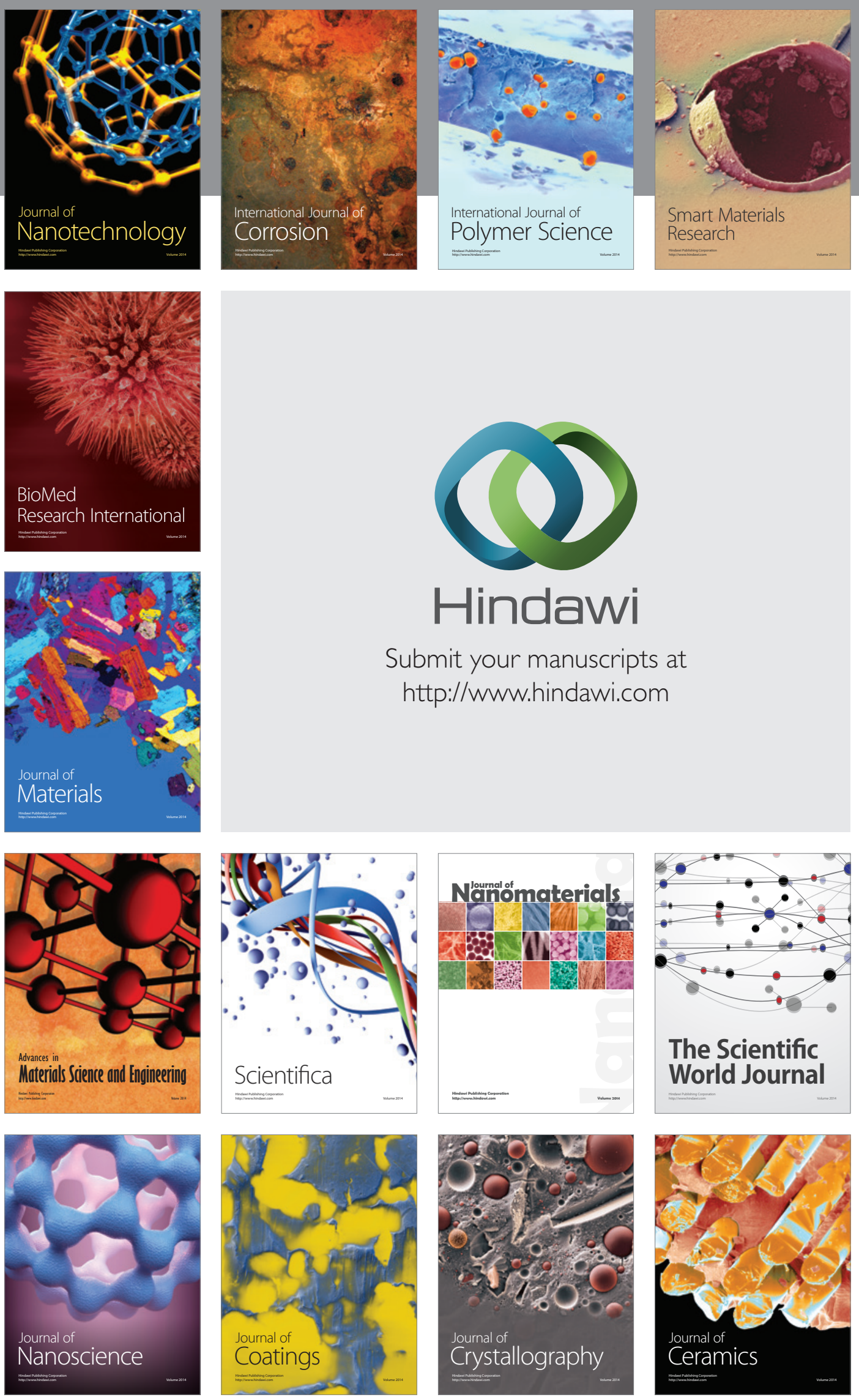

The Scientific World Journal

Submit your manuscripts at

http://www.hindawi.com

\section{World Journal}

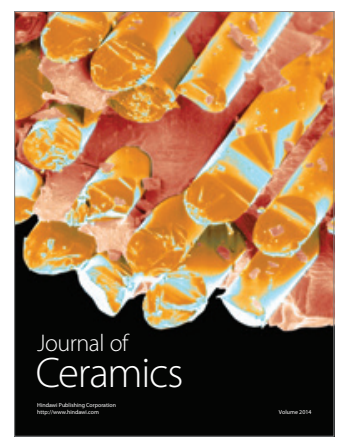

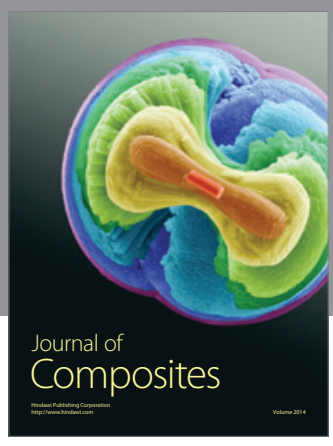
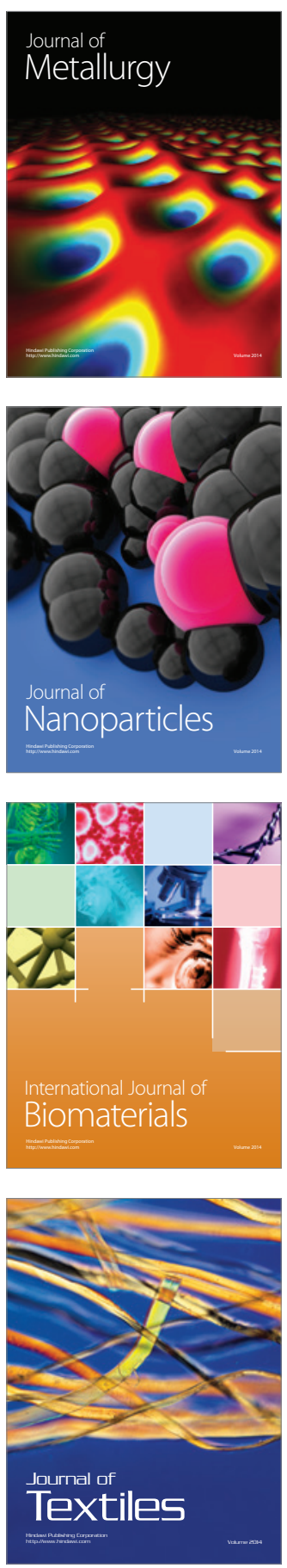